\title{
Effects of Free Gossypol and Cyclopropenoid Fatty Acids Present in the Feed on the Productivity, Quality, Elasticity, and Microstructure of Hens' Egg
}

\section{Dawei Chen}

Chinese Academy of Agricultural Sciences Poultry Institute https://orcid.org/0000-0002-1656-9360

\section{Yinyin Liu}

Chinese Academy of Agricultural Sciences Poultry Institute

\section{Lina Ma}

Chinese Academy of Agricultural Sciences Poultry Institute

Junhua Pu

Chinese Academy of Agricultural Sciences Poultry Institute

Junxian Lu

Chinese Academy of Agricultural Sciences Poultry Institute

\section{Xiujun Tang}

Chinese Academy of Agricultural Sciences Poultry Institute

\section{Rong Gu}

Chinese Academy of Agricultural Sciences Poultry Institute

\section{Shenghai Huang}

Chinese Academy of Agricultural Sciences Poultry Institute

\section{Hongmei Ding}

Chinese Academy of Agricultural Sciences Poultry Institute

\section{Yushi Gao ( $\nabla$ gaoys100@sina.com )}

Chinese Academy of Agricultural Sciences Poultry Institute https://orcid.org/0000-0002-3832-8672

\section{Research}

Keywords: Gossypol, cyclopropenoid fatty acid, elastic eggs, laying hens, vitelline membrane

Posted Date: October 8th, 2020

DOI: https://doi.org/10.21203/rs.3.rs-84922/v1

License: (c) (1) This work is licensed under a Creative Commons Attribution 4.0 International License. Read Full License 


\section{Abstract}

BACKGROUND: Free gossypol (FG) and cyclopropenoid fatty acids (CPFAs) are two main natural toxins in cottonseed meal(CSM). The increased yolk elasticity under cold storage conditions is related to the excessive CSM in the feed. However, which toxin caused the increased yolk elasticity is still not clear.

RESULTS: Our results show that the addition of FG or CPFA to the diet significantly reduced the egg production and feed conversion ratio. Besides, FG also resulted in a decrease in egg weight. The storage of eggs at $4{ }^{\circ} \mathrm{C}$ for four weeks resulted in a significant increase in elasticity and a decrease in the concentration of iron and calcium in the boiled yolks of CPFA and CSM groups when compared to the control. CPFA and CSM supplemented groups also showed an increase in pH and content of water in the yolk. Scanning electron microscopy (SEM) images from the CPFA and CSM groups revealed that the morphology of the vitelline membrane of eggs was characterized by different-sized holes. Furthermore, after four weeks of cold storage, the morphology of the vitelline granules in the CPFA and CSM supplemented groups were damaged; however, there were no significant alterations found in the FG group.

CONCLUSION: The main cause of the "sponge-bob egg" effect was the presence of CPFA in cottonseed meal, which causes an increase in permeability of the vitelline membrane in eggs.

\section{Introduction}

China is the largest producer of cotton worldwide. Cottonseed meal (CSM), a byproduct of oil extraction from cotton seeds, has long been considered as an alternative protein-rich animal feed due to the increasing costs of soybean meal. Although CSM is substantially lower in energy and protein than soybean meal, it can still be used successfully in layer diets because of their low energy and protein requirements when compared to broilers[1]. However, excess supplementation of CSM in poultry feed can be detrimental to egg quality, due to the presence of free gossypol (FG) and cyclopropenoid fatty acids (CPFAs) in CSM. Laying hens fed with a diet containing high levels of these natural toxins may produce eggs with pink albumen discoloration and brown yolks due to the presence CPFA and FG, respectively $[2,3,4,5,6]$.

Apart from the above mentioned harmful effects, too much CSM in the layer diet can also result in rubbery egg yolks. This phenomenon was first recorded by the local Chronicles office of Shanghai in 1982 [7], and was termed as the "SpongeBob egg" to describe yolks with increased elasticity after boiling. Similar phenomena have been reported increasingly in Chinese newspapers since 2001. In 2012 the Shanghai-based English news portal www.english.eastday.com published a report on a UK based investigation carried out by the consumer organization Watchdog into "rubber yolk" eggs. Our previous reports [8] demonstrated that eggs from laying hens fed with a diet comprising of $30 \% \mathrm{CSM}$ meal for four weeks and stored at $4{ }^{\circ} \mathrm{C}$ for seven days showed an increase in yolk elasticity when analyzed with high-quality texture analysis equipment (TMS-Pro), which was not the case for fresh (un-stored) eggs. The increase in elasticity was most evident after two weeks of cold storage [8]. Conversely, there was no significant change in the elasticity of the egg yolks in the control groups after storage at $4{ }^{\circ} \mathrm{C}$ for more than eight weeks. The mechanisms for the observed effects are, however, still unknown. In the present study, we speculated that natural toxins in CSM, principally FG, or CPFA might be responsible for the increased elasticity. To test this hypothesis, laying hens were fed with FG or CPFA separately to explore the cause and molecular mechanism of the "rubber yolk" phenomenon in cold-stored eggs.

\section{Materials And Methods}

\section{Collection of samples, dietary treatments, and bird management}

All experimental procedures were approved by the Animal Care and Use Committee of Poultry Institute, Chinese Academy of Agricultural Sciences (Yangzhou, Jiangsu, China). A total of 360 individually caged, 42 weeks old, Commercial Jinghong II laying hens were randomly assigned to 4 groups according to their respective diet treatments, with three repetitions per 
treatment (each replication had 30 hens). The dietary treatments were as follows: 1) the standard corn-soy layer control diet (Table 1); 2) standard control diet supplemented with free gossypol (Xi'an Bioherbix Co., LTD.) in the form of 400 mg acetate gossypol/kg final feed; 3) standard control diet supplemented with CPFA in the form of $300 \mathrm{mg}$ common sterculic acid methyl ester/kg final feed (Synthesized by BOC Sciences, USA), and; 4) standard control diet supplemented with CSM at a level of $30 \%$ of the final feed, as a positive control. The final content of free gossypol (FG) and CPFA was $186.48 \mathrm{mg} / \mathrm{kg}$ and $167.67 \mathrm{mg} / \mathrm{kg}$ in the CSM group according to the methods of HPLC and GC [9, 10]. Hens were provided with free access to water and feed during the experiment. The composition of the standard corn-soybean meal basal diet is shown in Table 1. Cages were randomly distributed in a ventilated room, and the temperature was maintained between 21 to $27^{\circ} \mathrm{C}$ with a light cycle of $16 \mathrm{~h}$ /day (10 to 20 lux). The experiment lasted for 13 weeks, including a one week acclimation period and a 12-week experimental period. The feed residues were collected and weighed weekly to estimate the average daily feed intake (ADFI). Eggs from each replicate group were counted and weighed daily to calculate the intensity of laying, average egg weight, and FCR. Mortality and health status of the hens were visually observed and recorded daily throughout the experimental period.

Table 1

Composition and nutrient levels of experimental diets (\%)

\begin{tabular}{|llllll|}
\hline Ingredients $\mathbf{( g / k g )}$ & \multicolumn{5}{l|}{ Nutrient (\%) } \\
\hline Item & Basal diet & $30 \%$ CSM & Item & Basal diet & $30 \%$ CSM \\
\hline Corn Grain & 63.2 & 55.5 & ME $\left(\mathrm{MJ} \mathrm{kg}^{-1}\right)$ & 11.10 & 11.09 \\
\hline Soybean Meal & 24.73 & - & Crude Protein & 16.13 & 16.17 \\
\hline Cotton Meal & - & 30 & Calcium & 3.31 & 3.30 \\
\hline Mineral Premix* & 4 & 4 & Non-phytate Phosphorus & 0.66 & 0.74 \\
\hline NaCl & 0.37 & 0.37 & Lys & 0.86 & 0.83 \\
\hline Oyster shell & 7 & 7 & Met & 0.38 & 0.38 \\
\hline rape oil & 0.5 & 1.8 & Free gossypol & - & 186.48 \\
\hline L-Lys HCL & 0.04 & 0.8 & CPFA(mg/kg) & \\
\hline DL-Met & 0.16 & 0.53 & & & 167.67 \\
\hline Total & 100 & 100 & & & \\
\hline
\end{tabular}

Table 1. Composition and nutrient levels of experimental diets (\%)

\section{Note}

ME, metabolism energy; Lys, lysine; Met, methionine; Cys, cysteine; *Supplied per kilogram of diet: vitamin A, 7000 IU; vitamin D 3, 2500 IU; vitamin E, 30 IU; vitamin K 3, 1 mg; vitamin B $1,1.5$ mg; vitamin B 2, 4 mg; vitamin B 6, 2 mg; vitamin B 12, $0.02 \mathrm{mg}$; niacin, $30 \mathrm{mg}$; folic acid, $0.55 \mathrm{mg}$; pantothenic acid, $10 \mathrm{mg}$; biotin, $0.16 \mathrm{mg}$; choline chloride, $400 \mathrm{mg} ; \mathrm{Cu}, 10 \mathrm{mg} ; \mathrm{Fe}$, 70 mg; Mn, 100 mg; Zn, 70 mg; I, 0.4 mg; Se, 0.5 mg. §Values were calculated from data provided by the Feed Database in China (2009)

\section{Productive performance and egg quality}

Egg productivity and the average egg weight of all replicate groups were calculated on the last day of the experimental period. The changes in the color of the collected eggs were examined, and the $\mathrm{pH}$ was determined using a Mettler Toledo PB10 pH meter after separating the yolks from the albumen. Subsequent tests were performed on freshly laid eggs (within 
$24 \mathrm{~h}$ of being laid), and eggs subjected to storage at $4{ }^{\circ} \mathrm{C}$ for 2,4 , and six weeks. The water content of the yolk in cold-stored eggs was measured by oven drying at $103^{\circ} \mathrm{C}$ for $24 \mathrm{~h}$.

The brown yolk discoloration was evaluated visually according to a fixed color standard ranging from " 0 " for none, " 1 " for very light brown (not objectionable) to " 8 " for black. Yolk mottling was scored on a 0-3 M grading system, where $3 \mathrm{M}$ represents severe mottling in patches that equates to a discoloration level of " 1 ". Pink albumen and apricot yolk discolorations were evaluated using similar visual tests.

\section{Determination of egg yolk elasticity}

Sixty eggs were collected from each dietary treatment group (20 from each replicate), once a week, throughout the experiment, and analyzed for their elasticity. The analysis was conducted on cooked (boiled) eggs, fresh eggs (laid within $24 \mathrm{~h}$ of the collection), and eggs stored at $4{ }^{\circ} \mathrm{C}$ for 2, 4, or 6 weeks. Eggs were cleaned using tap water and then placed in a pan and covered with tap water before boiling and simmering for $15 \mathrm{~min}$. The cooked yolks were then separated from the albumen. Yolk elasticity was assessed using an instrumental textural analyzer (TA-XT Plus Texture Analyzer, UK). Texture profile analysis (TPA) was conducted after fixing deformation percentages. The springiness of the eggs was evaluated according to springiness coefficients, which was calculated by dividing the springiness height by the target displacement.

\section{Determination of $\mathrm{Fe}$ and $\mathrm{Ca}$ in yolk and albumen}

Yolk and albumen samples were weighed when wet and digested with $5 \mathrm{~mL}$ of $65 \% \mathrm{HNO}_{3}$ mixed with $1 \mathrm{~mL}$ of $30 \% \mathrm{H}_{2} \mathrm{O}_{2}$ in a Teflon PFA microwave digestion vessel. All samples of the digest were diluted with deionized water to maintain the analyte within the calibration range. Graphite furnace atomic absorption spectroscopy was performed for the quantitative determination of $\mathrm{Ca}$ and Fe using a flame atomic absorption spectrometer (AS-800, PerkinElmer US).

\section{Scanning electron microscopy (SEM)}

The eggs were cracked open, and the yolks were separated from the white. The vitelline membrane and the yolk were then prefixed with $4 \%$ glutaraldehyde in $0.075 \mathrm{M}$ phosphate buffer $(\mathrm{pH} 7.0)$ at $4{ }^{\circ} \mathrm{C}$ for $8 \mathrm{~h}$. The specimens (yolk sphere and vitelline membrane) were sliced into approximately $2 \times 2 \times 5 \mathrm{~mm}^{3}$ pieces with a knife. After rinsing three times with the phosphate buffer (10 min each time), specimens were post-fixed with $1 \%$ osmium tetroxide in phosphate buffer at $4{ }^{\circ} \mathrm{C}$ for $24 \mathrm{~h}$. After rinsing twice in the same buffer (10 min each time), the post-fixed specimens were dehydrated successively in 20 , $40,60,80,95$, and $100 \%$ (3 times in 100\%) ethanol for 30 min each time. Samples were then subjected to critical-point drying with $\mathrm{CO}_{2}$ as the transition fluid, fractured, mounted, coated with $200 \AA$ gold-palladium, and examined using an SEM (S-4800, Hitachi, Japan). The accelerating voltage was not allowed to exceed $8 \mathrm{kV}$ to prevent local overheating of the sample.

\section{Statistical Analysis}

Data from the different dietary treatment groups are presented as mean \pm standard deviation and were analyzed by one-way ANOVA using SPSS18.0 software. Mean separation was achieved using Duncan's Multiple Range Test with the Least Significant Difference. $P$ values of less than or equal to 0.05 were considered significantly different.

\section{Results}

\section{Effects of FG and CPFA on productive performance}

As shown in Table 2, compared to the control group, there was a tendency toward a decline in ADFI in all three test groups; however, only after the eight-week, significant differences $(P<0.05)$ were found in FG and CPFA groups. Birds fed with $400 \mathrm{mg} / \mathrm{kg}$ of FG exhibited a lower intensity of laying than those in the control group from the fourth week onwards $(P<$ 0.05), whereas the egg-laying rate of those in the CPFA group decreased only in the twelfth week. The mean egg weights in the FG and CSM groups were significantly lower than in either the control or CPFA groups from the eighth week onwards $(P<$ 0.05); but, there was no significant difference in the mean egg weights between these two groups. Consistent with the 
observed effects on ADFI and egg production rate, the FCRs in FG and CPFA groups increased when compared to the control group, and the differences were significant from the fourth week onwards $(P<0.05)$.

Table 2

Effects of dietary supplementation with FG and CPFA on productive performance

\begin{tabular}{|c|c|c|c|c|c|}
\hline $\begin{array}{l}\text { Weeks post-dietary } \\
\text { supplementation }\end{array}$ & Groups & Control & FG & CPFA & $30 \% \mathrm{CSM}$ \\
\hline \multirow[t]{4}{*}{2} & ADFI (g) & $\begin{array}{l}120.12 \pm \\
2.54^{\mathrm{a}}\end{array}$ & $\begin{array}{l}117.45 \pm \\
3.45^{\mathrm{a}}\end{array}$ & $\begin{array}{l}118.31 \pm \\
3.57^{a}\end{array}$ & $\begin{array}{l}119.52 \pm \\
6.56^{a}\end{array}$ \\
\hline & Laying rate (\%) & $\begin{array}{l}88.81 \pm \\
2.21^{a}\end{array}$ & $\begin{array}{l}85.78 \pm \\
3.41^{\mathrm{b}}\end{array}$ & $\begin{array}{l}85.43 \pm \\
3.43^{b}\end{array}$ & $\begin{array}{l}88.14 \pm \\
3.34^{a}\end{array}$ \\
\hline & $\begin{array}{l}\text { Average egg weight } \\
\text { (g) }\end{array}$ & $\begin{array}{l}64.87 \pm \\
2.45^{\mathrm{a}}\end{array}$ & $\begin{array}{l}62.96 \pm \\
2.57^{a}\end{array}$ & $\begin{array}{l}64.93 \pm \\
2.51^{\mathrm{a}}\end{array}$ & $\begin{array}{l}62.86 \pm \\
4.47^{a}\end{array}$ \\
\hline & FCR (g:g) & $2.13 \pm 0.04^{a}$ & $2.36 \pm 0.02^{\mathrm{a}}$ & $2.37 \pm 0.06^{a}$ & $2.24 \pm 0.07^{a}$ \\
\hline \multirow[t]{4}{*}{4} & ADFI (g) & $\begin{array}{l}122.07 \pm \\
3.54^{\mathrm{a}}\end{array}$ & $\begin{array}{l}118.65 \pm \\
3.45^{b}\end{array}$ & $\begin{array}{l}118.31 \pm \\
3.57^{b}\end{array}$ & $\begin{array}{l}119.87 \pm \\
5.74^{a}\end{array}$ \\
\hline & Laying rate (\%) & $\begin{array}{l}91.35 \pm \\
7.34^{\mathrm{a}}\end{array}$ & $\begin{array}{l}84.81 \pm \\
6.47^{b}\end{array}$ & $\begin{array}{l}86.29 \pm \\
5.87^{\mathrm{b}}\end{array}$ & $\begin{array}{l}86.58 \pm \\
3.69^{b}\end{array}$ \\
\hline & $\begin{array}{l}\text { Average egg weight } \\
\text { (g) }\end{array}$ & $\begin{array}{l}65.66 \pm 1.24 \\
a\end{array}$ & $\begin{array}{l}58.76 \pm \\
5.15^{\mathrm{b}}\end{array}$ & $\begin{array}{l}65.51 \pm \\
1.45^{\mathrm{a}}\end{array}$ & $\begin{array}{l}60.49 \pm \\
5.14^{b}\end{array}$ \\
\hline & FCR (g:g) & $2.09 \pm 0.04^{a}$ & $2.57 \pm 0.04^{b}$ & $2.38 \pm 0.06^{b}$ & $2.47 \pm 0.09^{b}$ \\
\hline \multirow[t]{4}{*}{6} & ADFI (g) & $\begin{array}{l}121.14 \pm \\
4.54^{\mathrm{a}}\end{array}$ & $\begin{array}{l}119.95 \pm \\
3.65^{\mathrm{a}}\end{array}$ & $\begin{array}{l}119.31 \pm \\
3.57^{a}\end{array}$ & $\begin{array}{l}119.37 \pm \\
5.51^{a}\end{array}$ \\
\hline & Laying rate (\%) & $\begin{array}{l}88.91 \pm \\
4.34^{\mathrm{a}}\end{array}$ & $\begin{array}{l}84.91 \pm \\
5.42^{\mathrm{b}}\end{array}$ & $\begin{array}{l}85.34 \pm \\
8.45^{\mathrm{b}}\end{array}$ & $\begin{array}{l}85.63 \pm \\
4.17^{b}\end{array}$ \\
\hline & $\begin{array}{l}\text { Average egg weight } \\
\text { (g) }\end{array}$ & $\begin{array}{l}64.16 \pm \\
4.65^{a}\end{array}$ & $\begin{array}{l}58.89 \pm \\
3.57^{\mathrm{b}}\end{array}$ & $\begin{array}{l}65.34 \pm \\
2.56^{\mathrm{a}}\end{array}$ & $\begin{array}{l}59.37 \pm \\
1.58^{\mathrm{b}}\end{array}$ \\
\hline & FCR(g:g) & $2.13 \pm 0.04^{a}$ & $2.64 \pm 0.06^{b}$ & $2.48 \pm 0.05^{b}$ & $2.52 \pm 0.04^{b}$ \\
\hline
\end{tabular}

Table 2. Effects of dietary supplementation with FG and CPFA on productive performance

a,b Means within a line with different superscripts differ significantly $(P<0.05)$. tData points represent means from three replicates each of 30 laying hens. ADFI, Average daily feed intake; FCR, feed conversion ratio.

\section{Effects of FG and CPFA on egg quality}

As shown in Table 3, the storage of eggs at $4{ }^{\circ} \mathrm{C}$ for 2,4 , or 6 weeks resulted in the production of brown yolks, with most eggs in the CPFA and CSM groups showing moderate discoloration after four weeks of cold storage. Mottling is indicated in Table 3 by the letter " $M$ " after the score for yolk color, and brown discoloration is denoted by a number without a suffix. The $\mathrm{pH}$ of the yolk was also significantly higher in both the CPFA and CSM groups when compared to the control group $(P<$ 0.05). An increase in the storage period resulted in greater $\mathrm{pH}$ changes and more intense discoloration. In the discolored eggs, the yolks and albumen were found to be stuck together and were consequently more challenging to separate when compared to fresh eggs and non-discolored, cold-stored eggs from the control and FG groups. The increase in yolk pH in the CPFA group was accompanied by a corresponding but a smaller reduction in albumen $\mathrm{pH}$. Also, after two weeks of cold storage, there were signs of pink albumen discoloration observed in this group. A small number of yolks from the CPFA 
group appeared darker than the control; however, this effect was not statistically significant, and the eggs themselves were not considered objectionable in appearance. The water content of the yolk increased proportionately with the increase in the duration of egg storage in the CPFA and CSM groups. Yolk mottling did not occur in cold-stored eggs from any dietary group.

Table 3

Changes in egg discoloration, mottling and $\mathrm{pH}$ after cold storage at $4^{\circ} \mathrm{C}$

$\begin{array}{lllll}\text { Groups } & \text { Control } & \text { FG } & \text { CPFA } & 30 \% \text { CSM } \\ \text { Items } & & & \end{array}$

Fresh eggs

\begin{tabular}{lllll} 
Yolk color & 0 & 0 & 0 & 0 \\
\hline Albumen color & 0 & 0 & 0 & 0 \\
\hline Yolk PH & $5.95 \pm 0.08^{\mathrm{a}}$ & $6.10 \pm 0.07^{\mathrm{a}}$ & $5.95 \pm 0.09^{\mathrm{a}}$ & $5.98 \pm 0.07^{\mathrm{a}}$ \\
\hline Albumen PH & $8.79 \pm 0.20^{\mathrm{a}}$ & $8.90 \pm 0.05^{\mathrm{a}}$ & $8.78 \pm 0.08^{\mathrm{a}}$ & $8.88 \pm 0.06^{\mathrm{a}}$ \\
\hline Yolk water content (\%) & $49.57 \pm 3.22^{\mathrm{a}}$ & $49.61 \pm 2.61^{\mathrm{a}}$ & $49.97 \pm 2.54^{\mathrm{a}}$ & $49.54 \pm 2.54^{\mathrm{a}}$
\end{tabular}

Eggs stored at $4^{\circ} \mathrm{C}$ for 2 weeks

\begin{tabular}{lllll} 
Yolk color & 0 & 0 & $3 \mathrm{M}$ & $2 \mathrm{M}$ \\
\hline Albumen color & 0 & 0 & 5 & 4 \\
\hline Yolk PH & $6.10 \pm 0.07^{\mathrm{a}}$ & $6.11 \pm 0.11^{\mathrm{a}}$ & $6.61 \pm 0.13^{\mathrm{b}}$ & $6.57 \pm 0.25^{\mathrm{b}}$ \\
\hline Albumen PH & $9.10 \pm 0.03^{\mathrm{a}}$ & $9.08 \pm 0.05^{\mathrm{a}}$ & $8.71 \pm 0.19^{\mathrm{b}}$ & $8.76 \pm 0.17^{\mathrm{b}}$ \\
\hline Yolk water content (\%) & $50.14 \pm 2.45^{\mathrm{a}}$ & $50.47 \pm 2.67^{\mathrm{a}}$ & $51.87 \pm 4.64^{\mathrm{a}}$ & $51.38 \pm 3.67^{\mathrm{a}}$
\end{tabular}

Eggs stored at $4^{\circ} \mathrm{C}$ for 4 weeks

\begin{tabular}{lllll} 
Yolk color* & 0 & 0 & $8 \mathrm{M}$ & $6 \mathrm{M}$ \\
\hline Albumen color** & 0 & 0 & 10 & 10 \\
\hline Yolk PH & $6.12 \pm 0.32^{\mathrm{a}}$ & $6.04 \pm 0.13^{\mathrm{a}}$ & $7.99 \pm 0.52^{\mathrm{b}}$ & $7.87 \pm 0.46^{\mathrm{b}}$ \\
\hline Albumen PH & $9.34 \pm 0.03^{\mathrm{a}}$ & $9.32 \pm 0.05^{\mathrm{a}}$ & $8.95 \pm 0.04^{\mathrm{b}}$ & $8.92 \pm 0.18^{\mathrm{b}}$ \\
\hline Yolk water content $(\%)$ & $50.08 \pm 2.58^{\mathrm{a}}$ & $50.67 \pm 4.34^{\mathrm{a}}$ & $52.81 \pm 2.44^{\mathrm{b}}$ & $52.46 \pm 3.47^{\mathrm{b}}$
\end{tabular}

Eggs stored at $4^{\circ} \mathrm{C}$ for 6 weeks

\begin{tabular}{lllll} 
Yolk color & 0 & 0 & $10 \mathrm{M}$ & $10 \mathrm{M}$ \\
\hline Albumen color & 0 & 0 & 10 & 10 \\
\hline Yolk PH & $6.21 \pm 0.32^{\mathrm{a}}$ & $6.23 \pm 0.13^{\mathrm{a}}$ & $7.78 \pm 0.22^{\mathrm{b}}$ & $7.82 \pm 0.36^{\mathrm{b}}$ \\
\hline Albumen PH & $9.22 \pm 0.68^{\mathrm{a}}$ & $9.18 \pm 0.79^{\mathrm{a}}$ & $8.89 \pm 0.67^{\mathrm{b}}$ & $8.98 \pm 0.24^{\mathrm{b}}$ \\
\hline Yolk water content (\%) & $49.52 \pm 2.67^{\mathrm{a}}$ & $50.89 \pm 1.79^{\mathrm{a}}$ & $54.40 \pm 3.53^{\mathrm{b}}$ & $53.57 \pm 4.62^{\mathrm{b}}$
\end{tabular}

Each color and $\mathrm{pH}$ data point represents the mean of readings from 10 eggs. Yolk water content values represent the mean of 5 eggs. *Yolk color denotes the degree of brown discoloration whilst **albumen color denotes the degree of pink discoloration; * includes "rusty" brown yolks. M-denotes mottling. Values in the same horizontal line without common superscripts are significantly different $(P<0.05)$. 
Table 3. Changes in egg discoloration, mottling and $\mathrm{pH}$ after cold storage at $4^{\circ} \mathrm{C}$

\section{The elasticity of egg yolks after storage}

The fresh eggs from all groups were fractured after two cycles of extrusion when the texture analyzer was set at $25 \%$ deformation. After two weeks of cold storage, the egg yolks from the CPFA and CSM groups appeared to exhibit increased elasticity when compared to the control group, and after three or more weeks, the difference was significant. On the contrary, no changes in the elasticity of egg yolks were observed with cold storage in the FG and control group (shown in Fig. 1). As shown in Fig. 2 ( $a$ and b), yolks from the FG and control groups fractured easily after extrusion, while yolks from the CPFA and CSM groups remained intact without any chasms (Fig. 2c).

Figure 1. Effects of FG and CPFA on yolk springiness

Figure 2. Yolk elasticity determination

\section{The Content of Fe and $\mathrm{Ca}$ in the yolk and albumen}

Table 4 summarizes the concentrations of $\mathrm{Fe}$ and $\mathrm{Ca}$ in the albumen and yolk of eggs from different dietary treatment groups. The iron and calcium concentrations in the albumen of the CPFA group were significantly higher than the control group from the second week onwards. Conversely, concentrations of Fe and Ca in the yolk of the CPFA group decreased gradually with an increase in storage period when compared to the control group. No significant differences in Fe or Ca concentrations were observed between the FG and control groups.

Table 4

Concentration of Fe and $\mathrm{Ca}$ in eggs after cold storage for 2, 4 or 6 weeks

\begin{tabular}{|c|c|c|c|c|c|c|c|}
\hline \multirow[t]{2}{*}{ ITEM } & \multirow[t]{2}{*}{ Group } & \multicolumn{3}{|c|}{$\mathrm{Fe}(\mathrm{mg} / \mathrm{kg})$} & \multicolumn{3}{|l|}{$\mathrm{Ca}(\mathrm{mg} / \mathrm{kg})$} \\
\hline & & $2 W$ & $4 W$ & $6 W$ & $2 W$ & $4 W$ & $6 W$ \\
\hline \multirow[t]{4}{*}{ Albumen } & Control & $\begin{array}{l}0.87 \pm \\
0.02^{A}\end{array}$ & $\begin{array}{l}0.94 \pm \\
0.06^{A}\end{array}$ & $\begin{array}{l}1.08 \pm \\
0.05^{A}\end{array}$ & $93.62 \pm 7.14^{A}$ & $96.64 \pm 6.54^{\mathrm{A}}$ & $100.47 \pm 5.87^{\prime}$ \\
\hline & $\mathrm{FG}$ & $\begin{array}{l}0.89 \pm \\
0.01^{A}\end{array}$ & $\begin{array}{l}1.05 \pm \\
0.05^{\mathrm{A}}\end{array}$ & $\begin{array}{l}1.12 \pm \\
0.02^{\mathrm{A}}\end{array}$ & $94.24 \pm 6.84^{\mathrm{A}}$ & $97.18 \pm 5.14^{\mathrm{A}}$ & $99.98 \pm 6.25^{A}$ \\
\hline & CPFA & $\begin{array}{l}2.28 \pm \\
0.08^{\mathrm{B}}\end{array}$ & $\begin{array}{l}4.48 \pm \\
0.07^{B}\end{array}$ & $\begin{array}{l}5.83 \pm \\
0.14^{B}\end{array}$ & $156.14 \pm 3.67^{B}$ & $168.38 \pm 4.58^{\mathrm{B}}$ & $\begin{array}{l}317.29 \pm \\
10.24^{\mathrm{B}}\end{array}$ \\
\hline & $30 \% \mathrm{CSM}$ & $\begin{array}{l}1.89 \pm \\
0.06^{\mathrm{B}}\end{array}$ & $\begin{array}{l}3.87 \pm \\
0.12^{\mathrm{B}}\end{array}$ & $\begin{array}{l}4.69 \pm \\
0.22^{\mathrm{B}}\end{array}$ & $143.54 \pm 5.47^{B}$ & $156.51 \pm 8.14^{B}$ & $\begin{array}{l}307.48 \pm \\
11.53^{\mathrm{B}}\end{array}$ \\
\hline \multirow[t]{4}{*}{ Yolk } & Control & $\begin{array}{l}54.32 \pm \\
3.64^{\mathrm{a}}\end{array}$ & $\begin{array}{l}54.17 \pm \\
2.87^{a}\end{array}$ & $\begin{array}{l}51.43 \pm \\
3.24^{\mathrm{A}}\end{array}$ & $\begin{array}{l}1392.89 \pm \\
23.27^{A}\end{array}$ & $\begin{array}{l}1284.35 \pm \\
36.64^{A}\end{array}$ & $\begin{array}{l}1059.89 \pm \\
35.47^{A}\end{array}$ \\
\hline & $\mathrm{FG}$ & $\begin{array}{l}55.12 \pm \\
3.54^{\mathrm{a}}\end{array}$ & $\begin{array}{l}52.41 \pm \\
4.36^{a}\end{array}$ & $\begin{array}{l}50.22 \pm \\
2.87^{A}\end{array}$ & $\begin{array}{l}1402.67 \pm \\
41.25^{A}\end{array}$ & $\begin{array}{l}1373.24 \pm \\
41.36^{A}\end{array}$ & $\begin{array}{l}1009.67 \pm \\
39.17^{A}\end{array}$ \\
\hline & CPFA & $\begin{array}{l}48.24 \pm \\
2.11^{\mathrm{b}}\end{array}$ & $\begin{array}{l}44.57 \pm \\
3.14^{b}\end{array}$ & $\begin{array}{l}36.86 \pm \\
2.54^{\mathrm{B}}\end{array}$ & $\begin{array}{l}989.87 \pm \\
35.14^{\mathrm{B}}\end{array}$ & $\begin{array}{l}881.61 \pm \\
45.12^{\mathrm{B}}\end{array}$ & $\begin{array}{l}581.51 \pm \\
23.54^{\mathrm{B}}\end{array}$ \\
\hline & $30 \% \mathrm{CSM}$ & $\begin{array}{l}49.35 \pm \\
2.44^{\mathrm{b}}\end{array}$ & $\begin{array}{l}46.81 \pm \\
4.22^{b}\end{array}$ & $\begin{array}{l}40.34 \pm \\
2.87^{B}\end{array}$ & $\begin{array}{l}1024.57 \pm \\
43.54^{\mathrm{A}}\end{array}$ & $\begin{array}{l}984.67 \pm \\
34.47^{B}\end{array}$ & $\begin{array}{l}665.47 \pm \\
42.14^{B}\end{array}$ \\
\hline
\end{tabular}

Table 4. Concentration of Fe and Ca in eggs after cold storage for 2, 4 or 6 weeks 
After two weeks in the cage feeding trial, there were no apparent differences seen in the morphology of the yolk granules between the test and control groups under SEM (Fig. 3). All yolk granules had a regular shape and were homogeneous in size, with a smooth surface. Conversely, there were very few intact spheroidal yolk granules found in the yolk of eggs stored for six weeks at $4{ }^{\circ} \mathrm{C}$ from the CPFA group (Fig. 3e and f) and the CSM group (Fig. $3 \mathrm{~g}$ and h). After amplification, the egg yolks from these groups revealed irregular sharp particles and thin laminated structures. In summary, the structure of the vitelline membrane in the control group and the FG group was intact and dense (Fig. 4A and B), with virtually no holes (Fig. 4C and D). However, in the CPFA and CSM groups, different sized holes were observed to be distributed within the vitelline membrane (Fig. 4E to $\mathrm{H}$ ).

Figure 3. Scanning electron microscope for egg yolk granule

Control: a b; FG: c, d; CPFA: e, f; CSM: g, h.

Figure 4. Scanning electron microscope for vitelline membrane

Control: A, B; FG: C, D; CPFA: E, F; CSM: G, H.

\section{Discussion}

The inclusion of CSM in poultry feeds has been studied for decades. It has been found that high levels of CSM in the diet of laying hens can cause a deterioration in egg quality. In our previous research, we demonstrated that the "rubber egg" phenomenon is triggered by high levels of CSM in the diets of laying hens [8]. Gossypol (FG) and cyclopropenoid fatty acids (CPFAs) are the two main toxic substances found in CSM [11]. However, the component within the CSM which is responsible for the phenomenon remains unclear. In the present study, FG and CPFA were added separately to the diets of laying hens to investigate the causes and mechanisms involved in the "rubber egg" phenomenon. A high level of CSM was added to the diet via a different treatment group to act as a positive control. As expected, supplementation of the diet with FG or CPFA caused a reduction in productive performance when compared to the unsupplemented group. The intensity of laying and FCRs of the test groups both decreased but to different extents. Previous studies have shown that hens fed with diets containing FG at inclusion rates between $200 \mathrm{mg} / \mathrm{kg}$ and $400 \mathrm{mg} / \mathrm{kg}$ can result in a decrease in feed consumption, accompanied by a drop in egg production and egg size[12,13].

In this study, we further tested the effects of adding $100 \mathrm{mg} / \mathrm{kg}$ and $200 \mathrm{mg} / \mathrm{kg}$ of FG to the feed but found no significant difference in egg production (data not shown). However, the addition of $400 \mathrm{mg} / \mathrm{kg}$ of FG lowered the egg production rate from the fourth week onwards when compared to the control group. It has also been reported that CPFA can reduce egg production only at concentrations unattainable via incorporation of common plant products into laying hen diets[14]. In the present study, we used an artificially high concentration of $300 \mathrm{mg} \mathrm{CPFA} / \mathrm{kg}$ in the diet to obtain the observed effects on egg production. Moreover, egg production in the FG and CPFA groups were decreased significantly compared with the control group, but the reduction in the size of the eggs was observed only in the FG group.

The effects of FG and CPFA on egg production and discoloration were demonstrated in the present study. Many of the previous studies that investigated egg discoloration in relation to CSM inclusion in the diet used whole ground cottonseeds or CSM produced by screw press processing techniques, which left considerably more oil and FG in the meal [15]. Shenstone and Vickery (1959) [14]noted that egg yolks from hens fed with diets containing either malvalic acid or sterculic acid had surface colors of salmon or orange, a condition attributed to the formation of iron-conalbumin complexes which superimpose themselves on normal yolk pigments and produce pink-white discoloration. In the present study, we observed that a high content of CSM (as a positive control) caused a similar discoloration during cold storage. According to the results of Davis et al. (2002) [16] and Lordelo et al. (2007) [17], egg-yolk discoloration was positively associated with the presence of gossypol in the diet. However, here, we did not observe any apparent egg-yolk discoloration in the treatment group with added FG. This may be due to the lack of responsiveness of the hens to the egg discoloration effects of gossypolm [16]. The CSM and CPFA groups showed an increase in the occurrence and severity of pink albumen and yolk mottling in eggs that 
were under cold storage. These findings are in agreement with those of Kemmerer et al. (1963) [2]. When we tested the elasticity of the boiled yolks after storage at $4{ }^{\circ} \mathrm{C}$ for 2 to 6 weeks, it was found that only eggs from hens fed on diets containing CPFA showed changes (increase). These changes took place concurrently with the appearance of pink discoloration in the albumen.

To further explore the causes of the "rubber egg," we measured the changes in $\mathrm{pH}$ of the yolk and albumen along with the concentrations of Fe and $\mathrm{Ca}$. A modest increase in yolk pH coupled with a small increase in albumen $\mathrm{pH}$ was observed in the eggs from the CPFA and CSM groups, which is probably related to the presence of CPFA in the diet. However, the $\mathrm{pH}, \mathrm{Fe}$, and Ca concentrations in eggs from the FG and control groups were not affected. The pink albumen discoloration seen in cold storage eggs occurs after a relatively long period of storage because iron from yolk proteins must first diffuse out and combine with the albumen proteins [4]. In addition to iron, we found that other divalent ions, such as calcium, were also exchanged between the yolk and albumen.

Along with the observed changes in cation concentration, a higher yolk water content was also detected in the CPFA and CSM groups when compared to the control. Based on our results, we suggest that the adverse effects of a diet containing CPFA on egg quality can be explained by an increase in permeability of the vitelline membrane. Vitelline is a type of semipermeable membrane that prevents the passing of large molecules from the yolk into the albumen [18]. Due to the presence of the vitelline membrane, the $\mathrm{pH}$ of the yolk changes at a slower rate when compared to albumen. Water in the albumen increases the permeability of the vitelline membrane and facilitates the passage of molecules into the yolk; in turn, the salinity and carbon dioxide present in the yolk permeates into the albumen [19].

We further observed the ultrastructure of the vitelline membrane and yolk granules. It was found that there was a change in the structure of the vitelline membrane in the CPFA and CSM groups, with different-sized holes distributed inside the vitelline membrane. The yolk granules in the CPFA group lost their normal structure and became irregularly shaped with thin slices after more than four weeks of cold storage. The ultrastructure of the granules in the egg yolk depends very much on the physicochemical characteristics of the surrounding medium, such as $\mathrm{pH}$, ionic strength, and concentration of bivalent cations [20]. According to Causeret's study, the modification of one of these parameters was sufficient to destructure the granules irreversibly. Here, we found that the $\mathrm{pH}$ of the yolk in the CPFA and CSM groups increased significantly while the concentration of calcium and iron decreased. These effects were accompanied by a partial destabilization of the microstructure of the yolk granules.

\section{Conclusions}

In conclusion, our results suggest that CPFA, and not free gossypol, causes the formation of yolks with increased elasticity, also known as "SpongeBob egg." Furthermore, we observed that CPFAs altered the permeability of the yolk-vitelline membrane, resulting in the migration of mineral cations (calcium and iron) and protein through the vitelline membrane while facilitating the transfer of water from the albumen to the yolk and equilibrating the $\mathrm{pH}$ in the egg white and yolk. Our results indicate that all of these effects contribute to the destruction of yolk granules and leads to elastic gel formation, which is consistent with the phenomenon of "Sponge Bob egg."

\section{Declarations}

- Ethics approval and consent to participate : Not applicable.

- Consent for publication : Not applicable.

- Availability of data and materials : All data generated or analyzed during this study are included in this published article.

- Competing interests: The authors declare that they have no competing interests.

- Funding : This research was supported by the National Key R\&D Program of China (2016YFD0501208). 
- Authors' contributions: DWC, YSG designed the study; YYL, LNM, JHP, JXL, RG, SHH, HMD performed the animal feeding experiment and samples analysis; DWC, YSG wrote the manuscript; DWC, YSG analyzed the data. All the authors read and approved the final manuscript.

- Acknowledgements: Not applicable.

\section{References}

1. Jones LA. Nutritional values for cottonseed meal. Feedstuffs. 1981;53(52):19-21.

2. Kemmerer AR, Heywang BW, Vavich MG, Phelps RA. Further studies of the effect of cottonseed oil on discoloration of cold storage eggs. Poult Sci. 1963;42:893-5.

3. Kemmerer AR, Heywang BW. Effect of the Addition of Cottonseed Lipids to Cottonseed Meal on Egg Discoloration. Poult Sci. 1965;44:888-90.

4. Panigrahi S, Plumb VE. Effects on dietary phosphorus of treating cottonseed meal with crystalline ferrous sulfate for the prevention of brown yolk discoloration. Br Poult Sci. 1996;37(2):403-11.

5. Kemmerer AR, Heywang BW, Vavich MG. Effect of Sterculia foetida oil on gossypol discoloration in cold storage eggs and the mechanism of gossypol discoloration. Poult Sci. 1961;40:1045-8.

6. Schaible PJ, Moore LA, Moore JM. Gossypol, a Cause of Discoloration in Egg Yolks. Science. 1934;79(2051):372.

7. Log of Shanghai commodity inspection. Third chapter; fourth quarter, Fresh egg and processing eggs. http://www.shtong.gov.cn/node2/node2245/node67984/node67989/node68007/node68060/userobject1ai65289.html.

8. Gao YS, Tang MJ, Lu JX, et al. Effects of High Cottonseed Meal on Production Performance and Egg Quality in Laying Hens. China Poultry. 2012;34(6):16-9.

9. Shi ZH, Tang MJ, Zhang XY, et al. Determination of Gossypol in Poultry Egg and Feed by Automated Solid-Phase Extraction and High-Performance Liquid Chromatography. Asian journal of chemistry. 2013;25(8):4547-50.

10. Mitchell B, Michalica D, Sabbatini J, Rozema B. Determination of nutritional and cyclopropenoid fatty acids in cottonseed by a single GC analysis. Journal of the American Oil Chemists' Society. 2015;92(7):947-56.

11. Economic cooperation and development organization consensus document: Consensus Document on Compositional Considerations for New Varieties of Cotton (Gossypium hirsutum and Gossypium barbadense): Key Food and Feed Nutrients and Anti-nutrients"

Economic cooperation and development organization consensus document: Consensus Document on Compositional Considerations for New Varieties of Cotton (Gossypium hirsutum and Gossypium barbadense): Key Food and Feed Nutrients and Anti-nutrients". Copyright OECD, Accessed 2004.

12. Narain R, Lyman CM, Couch JR. High levels of free gossypol in hen diets: effects on body weight, feed consumption, and egg production. Poult Sci. 1957;36:1351-4.

13. Waldroup PW, Goodner TO, Sloan DR. Use of cottonseed meal in diets for commercial egg production. Feedstuffs. 1970;April:20-2.

14. Shenstone FS, Vickery JR. Substances in plants of the order Malvale causing pink whites in stored eggs. Poult Sci. 1959;38:1055-70.

15. Panigrahi S, Plumb VE, Machin DH. Effects of dietary cottonseed meal, with and without iron treatment, on laying hens. Br Poult Sci. 1989;30:641-51.

16. Davis AJ, Lordelo MM, Dale N. The use of cottonseed meal with or without added soapstock in laying hen diets. Journal of Applied Poultry Research. 2002;11:127-33.

17. Lordelo MM, Calhoun MC, Dale NM, Dowd M, K,Davis AJ. Relative toxicity of gossypol enantiomers in laying and broiler breeder hens. Poult Sci. 2007;86(3):582-90. 
18. De Cássia RS, Sousa JSR, Coimbra EE, Garcia Rojas LA, Fabíola C. Oliveira Valéria PR, Minim. Effect of pH and salt concentration on the solubility and density of egg yolk and plasma egg yolk. LWT - Food Science Technology. 2007;40(7):1253.

19. Fabien G, Ulrich K. Impact of a thermal treatment on the emulsifying properties of egg yolk. Part 2: Effect of the environmental conditions. Food Hydrocolloids. 2006;20(8):1114.

20. Causeret D, Matringe E, Lorient DI. Strength and pH Effects on Composition and Microstructure of Yolk Granules. J Food Sci. 1991;56(6):1532-6.

\section{Figures}

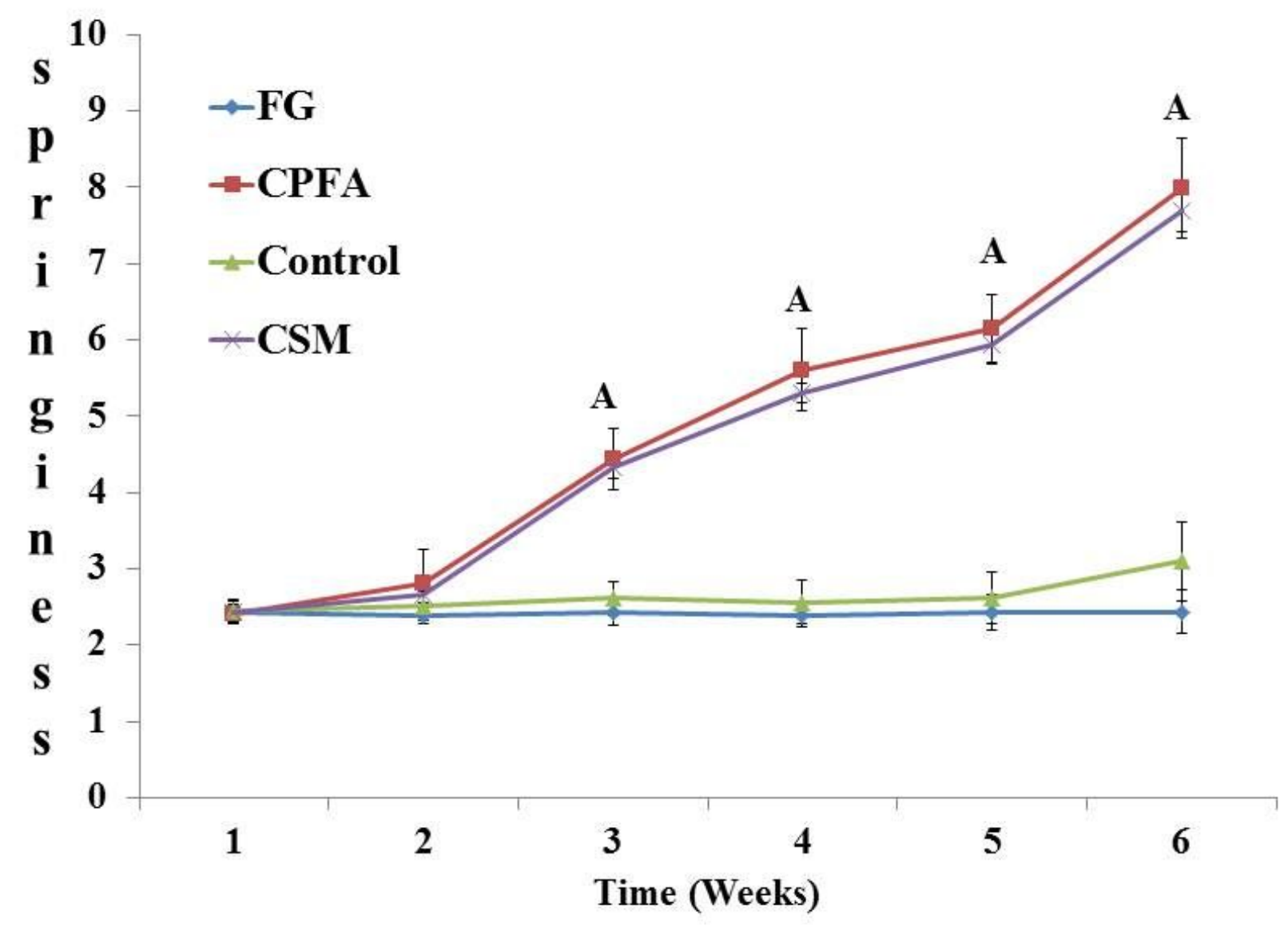

Figure 1

Effects of FG and CPFA on yolk springiness 


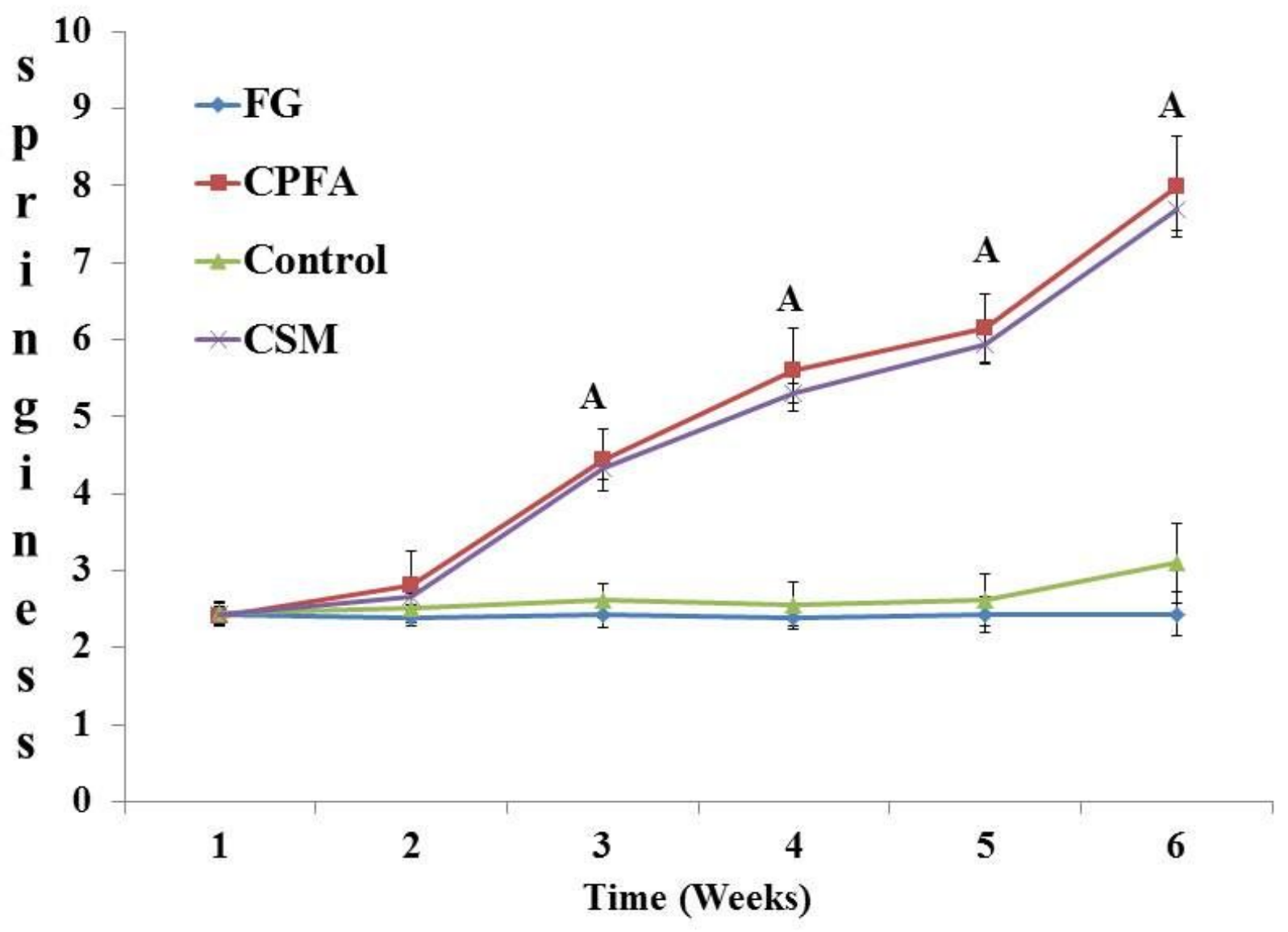

Figure 1

\section{Effects of FG and CPFA on yolk springiness}
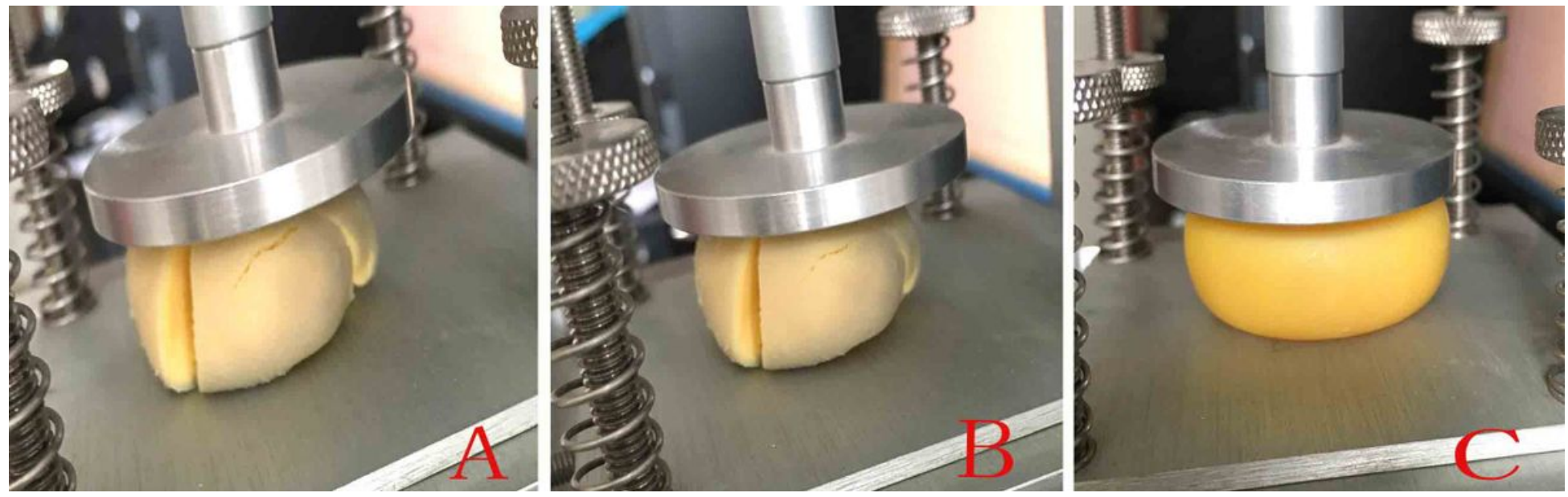

Figure 2

Yolk elasticity determination 

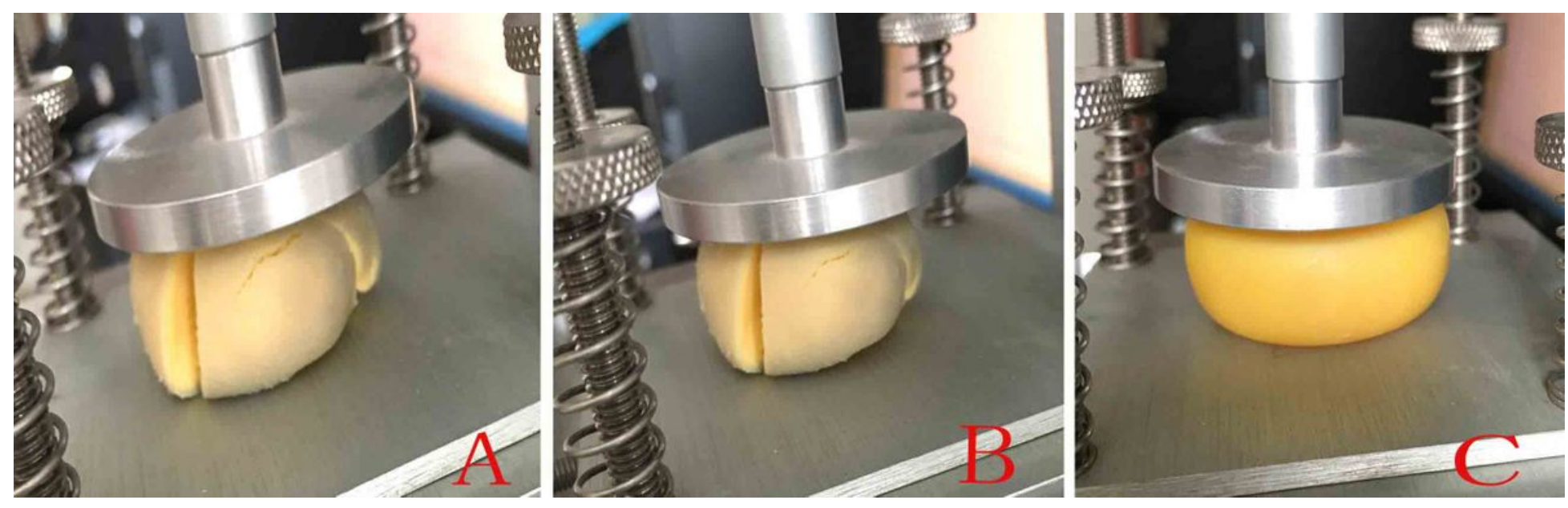

Figure 2

Yolk elasticity determination 


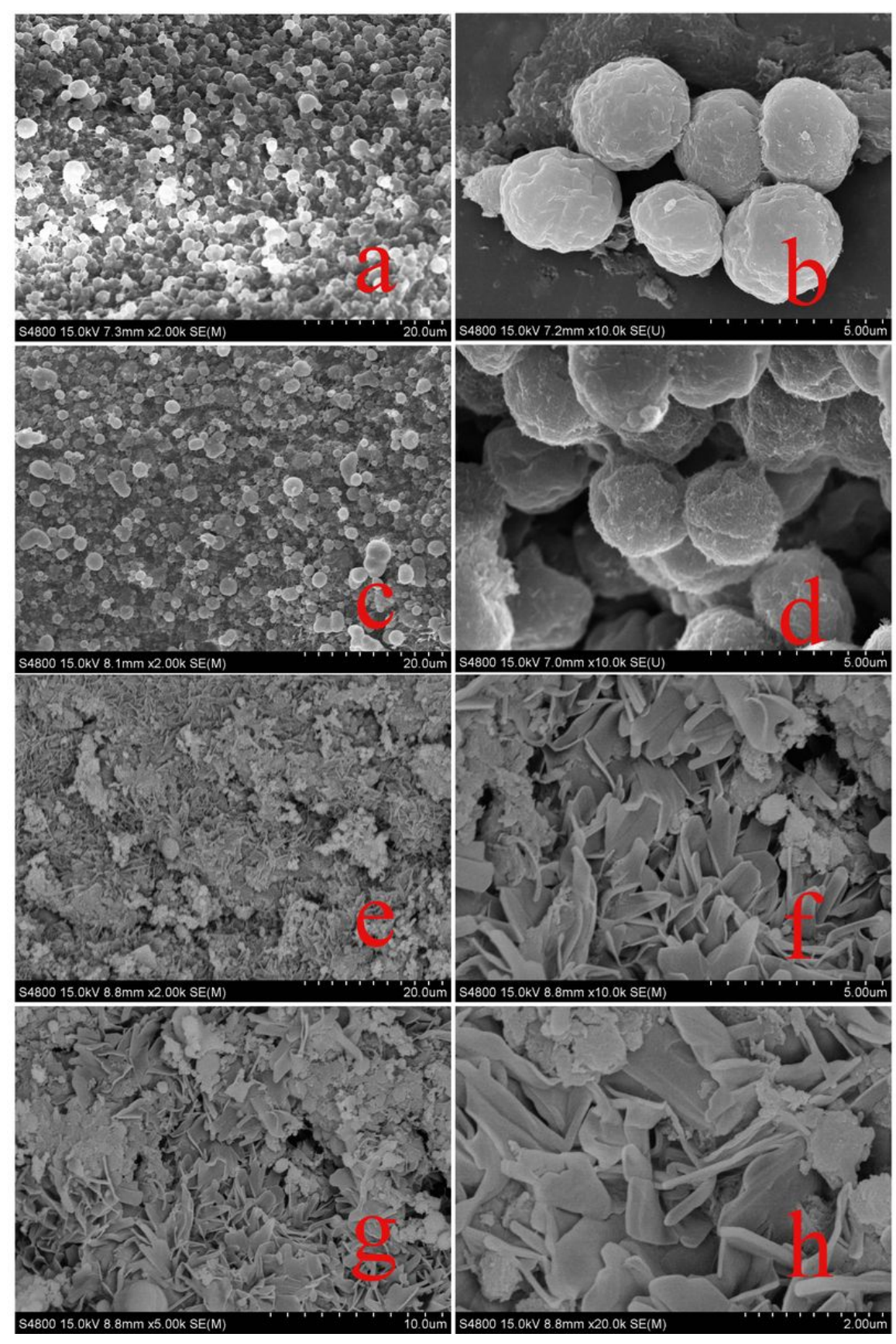

Figure 3

Scanning electron microscope for egg yolk granule Control: a b; FG: c, d; CPFA: e, f; CSM: g, h. 


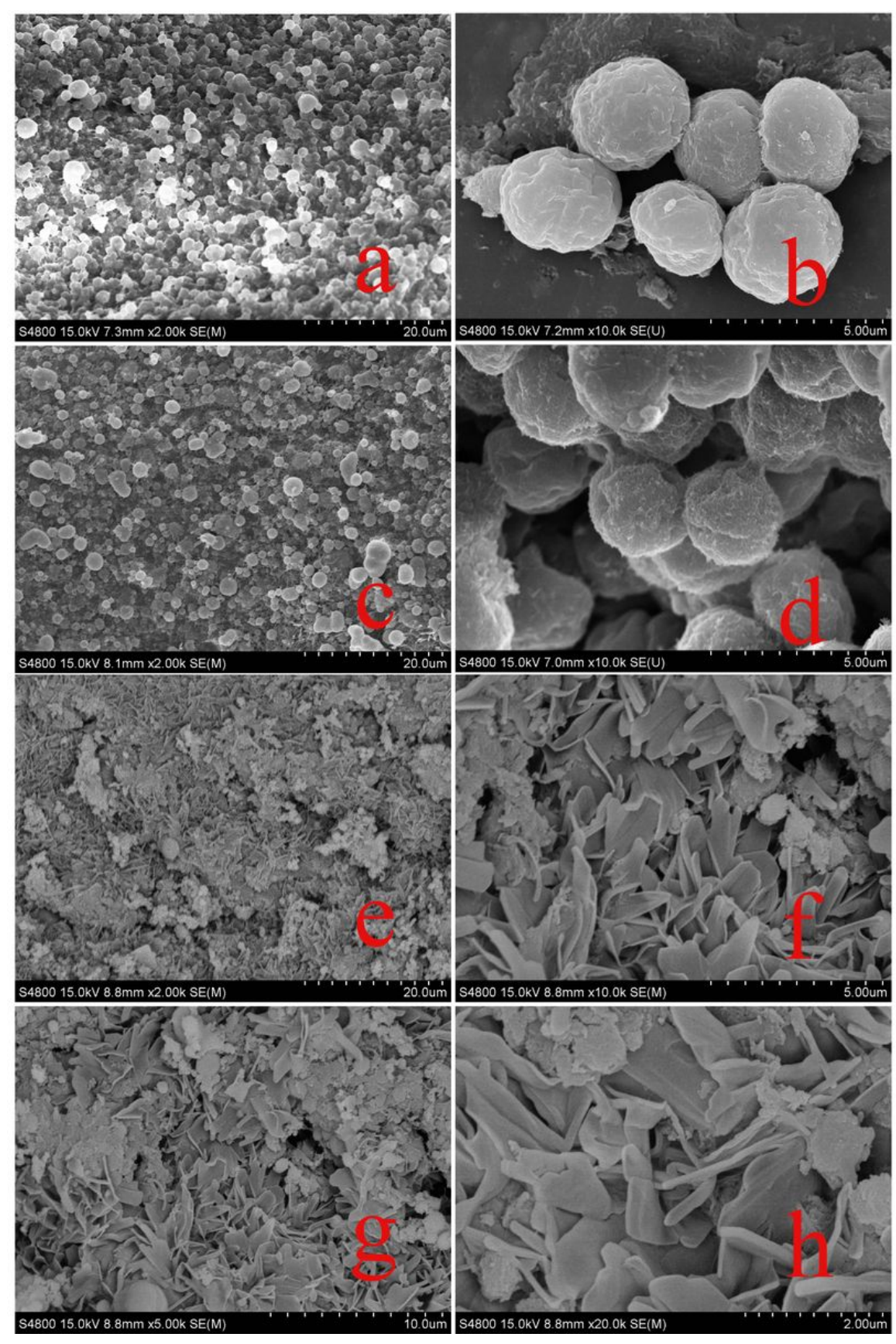

Figure 3

Scanning electron microscope for egg yolk granule Control: a b; FG: c, d; CPFA: e, f; CSM: g, h. 

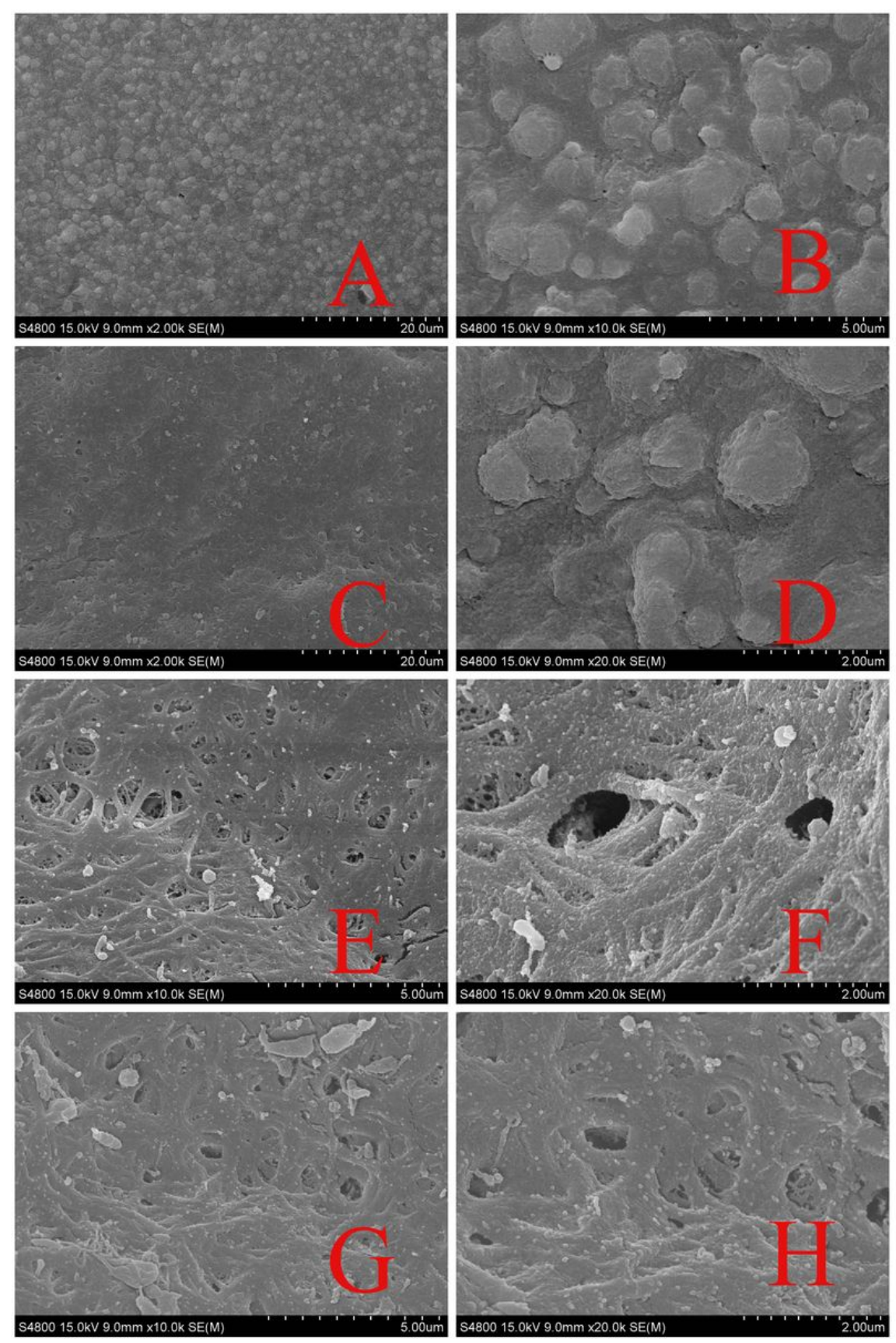

Figure 4

Scanning electron microscope for vitelline membrane Control: A, B; FG: C, D; CPFA: E, F; CSM: G, H. 

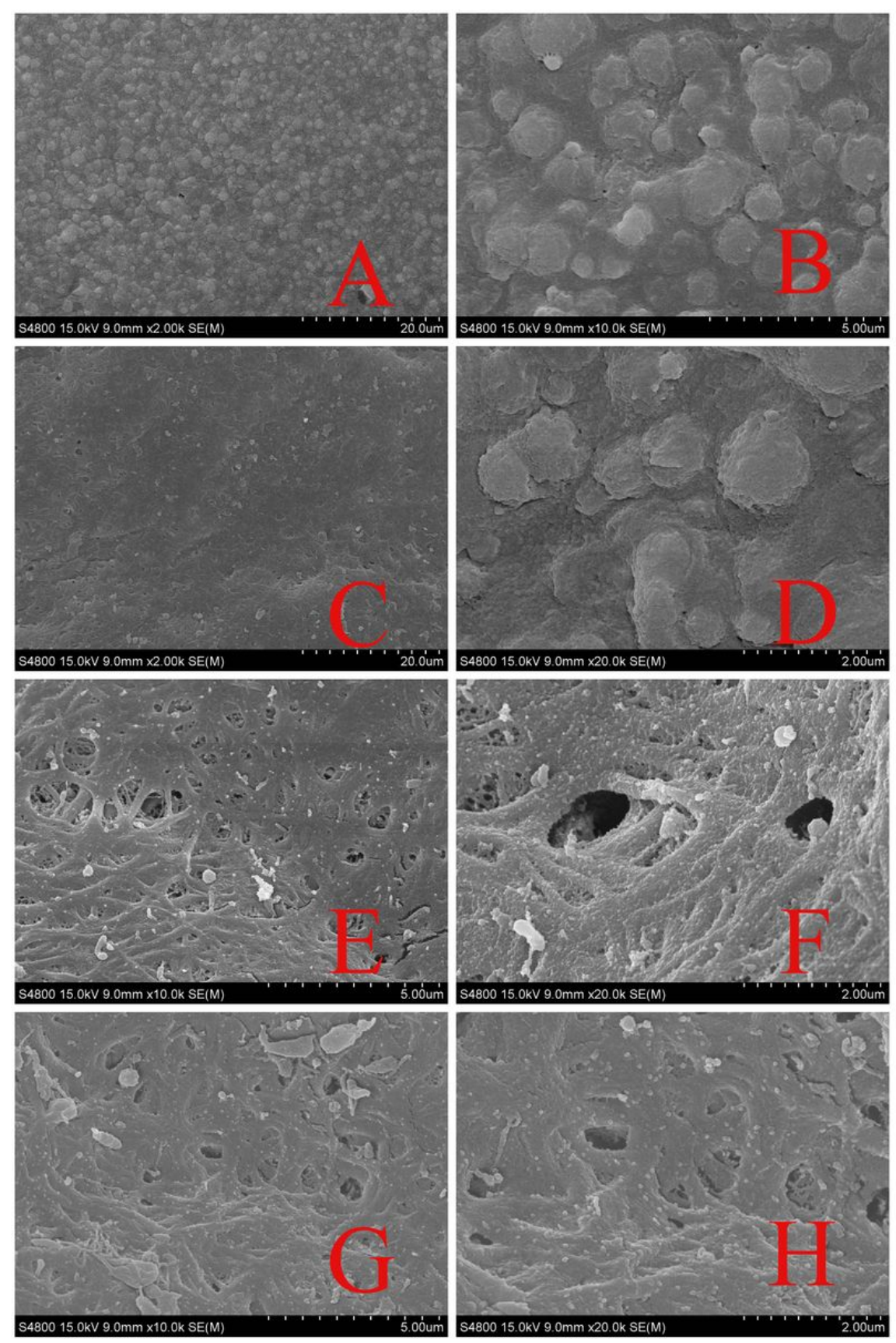

Figure 4

Scanning electron microscope for vitelline membrane Control: A, B; FG: C, D; CPFA: E, F; CSM: G, H. 